\title{
Digital Board Game Using the Theory of Variation to Enhance Grammar Learning
}

\author{
Tengku Nazatul Shima Tengku Paris ${ }^{1}$, Maimunah Abdul Kadir ${ }^{2}$ \\ 1 Universiti Teknologi MARA Pahang, Raub Campus, 27600, Raub, Pahang, Malaysia \\ 2 International Islamic University, Jalan Gombak,53100 Selangor, Malaysia \\ shimaparis@gmail.com, maimunah@iium.edu.my \\ 0199515668:
}

\begin{abstract}
The study is on the use of Throw Back Time (TBT), an interactive digital board game aimed at teaching grammar tenses and aspect. The game exclusively designed according to the Theory of Variation (Marton \& Booth, 1997). Four patterns of variation including contrast, separation, generalization, and fusion were used. The study employed a qualitative content analysis in illuminating the principles of the Theory of Variation (ToV) in the design of the grammar exercises in the game. Hence, the study suggests that the elements in the (ToV) governing the tasks in the game delivers positive outcomes to help learners learning grammar.
\end{abstract}

Keywords: Grammar; The Theory of Variation; Interactive; Digital learners

eISSN: 2398-4287 @ 2019. The Authors. Published for AMER ABRA cE-Bs by e-International Publishing House, Ltd., UK. This is an open access article under the CC BYNC-ND license (http://creativecommons.org/licenses/by-nc-nd/4.0). Peer-review under responsibility of AMER (Association of Malaysian Environment-Behaviour Researchers), ABRA (Association of Behavioural Researchers on Asians) and cE-Bs (Centre for Environment-Behaviour Studies), Faculty of Architecture, Planning \& Surveying, Universiti Teknologi MARA, Malaysia.

DOI: https://doi.org/10.21834/e-bpj.v4i12.1894

\subsection{Introduction}

The study is a continuation from the researcher's previous research on the use of a digital board game "Throw Back Time (TBT) via Mobile Assisted Language Learning (MALL). The last research emphasized on the results from the pre, and post-test scores of grammar test after the respondents received treatment on TBT via MALL. The current study, however, describes how the elements from the Theory of Variation (TOV) support the design of the questions in TBT.

English language is the most significant second language and also the medium of instruction and communication in many nonEnglish speaking countries. In Malaysia, English is made compulsory in Primary School Standard Curriculum (KSSR) and Secondary School Standard Curriculum (KSSM). However, not all learners are capable of being operationally proficient in English, and there has been a decline in the standard of English language among learners over the years (Shuib, 2013; Shuib, 2015; Ganapathy et al., 2016; Rozina et al., 2017; Mahalingam, 2017).

Proficiency in English entails knowing grammar rules, a crucial requirement in mastering the language (Larsen-Freeman, 1991; Larsen-Freeman, 2015; Harmer, 1991; Chomsky \& Halle, 1991; Ur, 1996; Matsumoto \& Dobs, 2017; Bikowski, 2018). To achieve this mastery is unfortunately not an easy feat as grammar is often a problematic component for learners of English a second or foreign language to acquire (Embi \& Amin, 2010; Matsumoto \& Dobs, 2017). Grammar is full of rules that can be overwhelming for learners to learn and memorize while teachers often take the conventional approach in explaining the detailed practices to the learners.

The establishment of the Education Blueprint from 2015-2025 is to deliver the best possible instruction for learners. One of the aims is to incorporate technology into the teaching and learning environment. Technology is much emphasized here due to its promising value in teaching and learning (Sanchez \& Olivares, 2011; Klopfer et al., 2011; Bazzaza et al., 2016; Krasniuk \& Kryvych, 2016).

eISSN: 2398-4287 @ 2019. The Authors. Published for AMER ABRA cE-Bs by e-International Publishing House, Ltd., UK. This is an open access article under the CC BYNC-ND license (http://creativecommons.org/licenses/by-nc-nd/4.0/). Peer-review under responsibility of AMER (Association of Malaysian Environment-Behaviour Researchers), ABRA (Association of Behavioural Researchers on Asians) and cE-Bs (Centre for Environment-Behaviour Studies), Faculty of Architecture, Planning \& Surveying, Universiti Teknologi MARA, Malaysia. DOI: https://doi.org/10.21834/e-bpj.v4i12.1894 
To elevate the learning potential and to meet the demand of digital learners of today, the researcher had developed an interactive digital board game via mobile technology called Throw Back Time (TBT). The Theory of Variation (Marton \& Booth, 1997) supports the development of the game. According to Marton and Booth (1997), the fundamental aspect of learning is for students to notice the critical issue through variation and not sameness. This principle is the essence of the Theory of Variation that acts as a guiding principle in the design of grammar questions in the game that was used as a teaching aid in this study to teach TESL Foundation students Universiti Teknologi MARA (UiTM Dengkil). The items were arranged in a manner that the characters, actions and events in the sentences remained constant, still, the linguistic and discourse aspect of the sentences varied to ensure learners discerned the critical features related to tenses and aspect. The development of the questions for the game was outlined. It ultimately investigates if the game can create a stimulating and non-threatening setting to learn and improve their knowledge of grammar tenses and aspect. TBT is a digital board game where players have to correct errors of grammar tenses and aspect. Elements of challenge, competition, motivation and reward are included in the game to create a fun and engaging learning environment.

There are several studies in language learning and grammar that have successfully benefited from the Theory of Variation. The studies include teaching reading (Tong, 2012), writing (Thorsten, 2015), present tense (Annie, 2011), present perfect (Annie, 2011; Roy, 2014), adverb (Roy, 2014), present continuous (Lindström, 2017) and present perfect (Ott, 2017). However, many other studies that utilize the Theory of Variation focus on natural science class (Lo, 2012; Ott, 2017) and not many studies have focused on tenses and aspect (Ott, 2017). To address the gap, the researcher had used the elements in the Theory of Variation to design grammar tenses and aspect questions in the TBT game.

\subsection{Literature Review}

The Theory of Variation propagates that students comprehend, experience and think differently on a specific aspect of the world due to their background knowledge and current understanding (Marton and Booth, 1997). Students have different ideas and expectations of what educators deliver. Therefore, variations in learning outcomes are necessary. Thus, educators should plan their teaching approaches in an intended way (Marton \& Tsui, 2004).

Accurately, educators should meticulously plan on what to teach (the object of learning) and introduce appropriate teaching approaches that are capable of holding students' interest. "An object of learning is a specific insight, skill, or capability that the learners have to acquire in a lesson or during a limited sequence of lessons" (Marton \& Pang, 2006, p. 194). The concept asserts that all intellectual actions should focus on an object. Learning is often about acquiring knowledge, and we cannot deviate from considering what to teach. Thus, variation should be used as a guideline so that the "object of learning" is exposed in an intended way. Students should have a chance to concentrate on the critical elements independently or cooperatively using the variation model (Bowden \& Marton, 1998). Essential aspects that have yet to be discerned by students are known as critical aspects. The essential elements are connected to the object of learning and to the students who are involved (Marton, 2015). It is vital to search for these essential aspects of teaching purposes. The critical aspects of this study are in understanding the usage of grammar tenses and aspect.

Different sequences of variation occur through a variety of combinations and structures. Students will then be able to concentrate on various aspects of the object of learning. The various elements can be materialized by varying one or a few elements and keeping certain aspects unchanged. For students to notice and discern the structure that we want them to learn, it has to vary against an invariant background. In short, what we want the students to learn (the object of learning) is contrasted with what we do not.

Different teaching materials that educators keep in the classroom and the approaches they utilize will affect what and how learners learn (Bowden \& Marton, 1998; Marton, 2015). Several studies by Marton and Morris (2002), Marton and Tsui (2004), Annie (2011) and Lindström (2017) believe that educators who use the Theory of Variation are likely to be successful in teaching compared to those who do not use the theory. There are four patterns of variation that include contrast, separation, generalization and fusion (Marton \& Runesson, 2003). Each model indicates different things, for example:

Contrast - determining variation between two values

Separation - setting apart aspect with varying values from invariant aspects

Generalization - allowing varied appearances of the same value

Fusion - having several critical elements at the same time (Marton et al., 2004, p.16-17)

\subsection{Studies that Employed Theory of Variation}

The study by Annie (2011) gives some examples on the patterns of variation: students can be presented with the "past tense" by comparing and contrasting the past tense with the "present perfect aspect" in the capacity of tense variation. Next, students can separate the past tense and the present perfect aspect by varying the use of sentences using different time markers and contextual clues. The Separation will enable the students to generalize various features of the tenses and their connection with other invariants. Lindström (2017) who teaches present progressive highlights that by comparing two tenses simultaneously in a different way, the meaning of present progressive more apparent to learners and enhances their possibility to learn two tenses at the same time is better than one. Thorsten (2015) believes that the elements in the variation theory help teachers to prepare an adequate pedagogical design which assists learners in learning. However, Lo, (2012) stresses that using the features of variation cannot guarantee learning discernment. Teachers firstly have to find learners' problems in learning and assist them in establishing powerful ways of seeing the relevant elements of what to learn that at the same time will help them to improve their difficulties in learning.

There are several studies in language learning and grammar that have successfully benefited from the Theory of Variation. The studies include teaching reading (Tong, 2012), writing (Thorsten, 2015), present tense (Annie, 2011), present perfect (Annie, 2011; Roy, 
2014), adverb (Roy, 2014), present progressive (Lindström, 2017) and present perfect (Ott, 2017). However, many other studies that utilize the Theory of Variation focus on natural science class (Lo, 2012; Ott, 2017) and not many studies have focused on tenses and aspect (Ott, 2017; Lindström, 2017). To address the gap, the researcher had used the elements in the Theory of Variation to design grammar questions in the Throw Back Time (TBT) digital game.

\subsection{Methodology}

The study used a qualitative data analysis where a content analysis was employed to clarify how the elements in the Theory of Variation supported the design of the questions in the digital board game. Each type of question in the game was described according to the specification taken from the theory including the elements of contrast, separation, generalization and fusion. Each item helped to support the tenses and aspect grammar questions in TBT game.

The sample population for this research was selected based on a purposive sampling of the Teaching English as a Second Language (TESL) Foundation Programme students of Universiti Teknologi MARA (UiTM) Dengkil Campus who enrolled into the programme in May 2016. There were 47 subjects in the group that were randomly grouped into 23 pairs, with one participant having to work alone. Each pair was given a seven-inch tablet on a loan basis during the ten weeks of the experiment. The instrument is the digital board game Throw Back Time (TBT) uploaded in the tablet. TBT consists of 664 grammar questions, and the questions were adapted from UiTM textbooks. The content development of the items and the game had gone through, systematic, rigorous and appropriate assessment evaluation in the preliminary work of the research. Firstly, the questions were edited by an experienced English language acquisition and grammar professor. Secondly, during the developmental stage of the questions in the TBT, the researcher also sought the advice and worked closely with the expert of the Theory of Variation, Professor Mun Ling Lo from Hong Kong University via email. Each type of question was checked, commented and amended by Professor Mun to ensure that the questions complied with the specifications of the theory. The specifications include the elements of contrast, separation, generalization and fusion. Thirdly, two experts in Computer Science and Mobile Learning were also assigned to examine the design of the digital board game. Their comments and suggestions helped further in improving the design of the game. The feedback from the expert on the Theory of Variation and the input from the expert on Computer Science and Grammar were essential in the study. The feedback and input ensure that the game content was in line with the principles of the theory, the game design, the learning approaches and the language acquisition.

The case study involved first semester TESL foundation students of UiTM Dengkil. Hence, the generalization of the findings should be evaluated within the confines of the setting of the study.

\subsection{Findings}

There are 664 sets of questions in the digital board game based on six formats, and for this paper, the researchers only highlight on the first three formats, which are two-answer options, three-answer options and four-answer options. The illustrations of the forms are as follows:

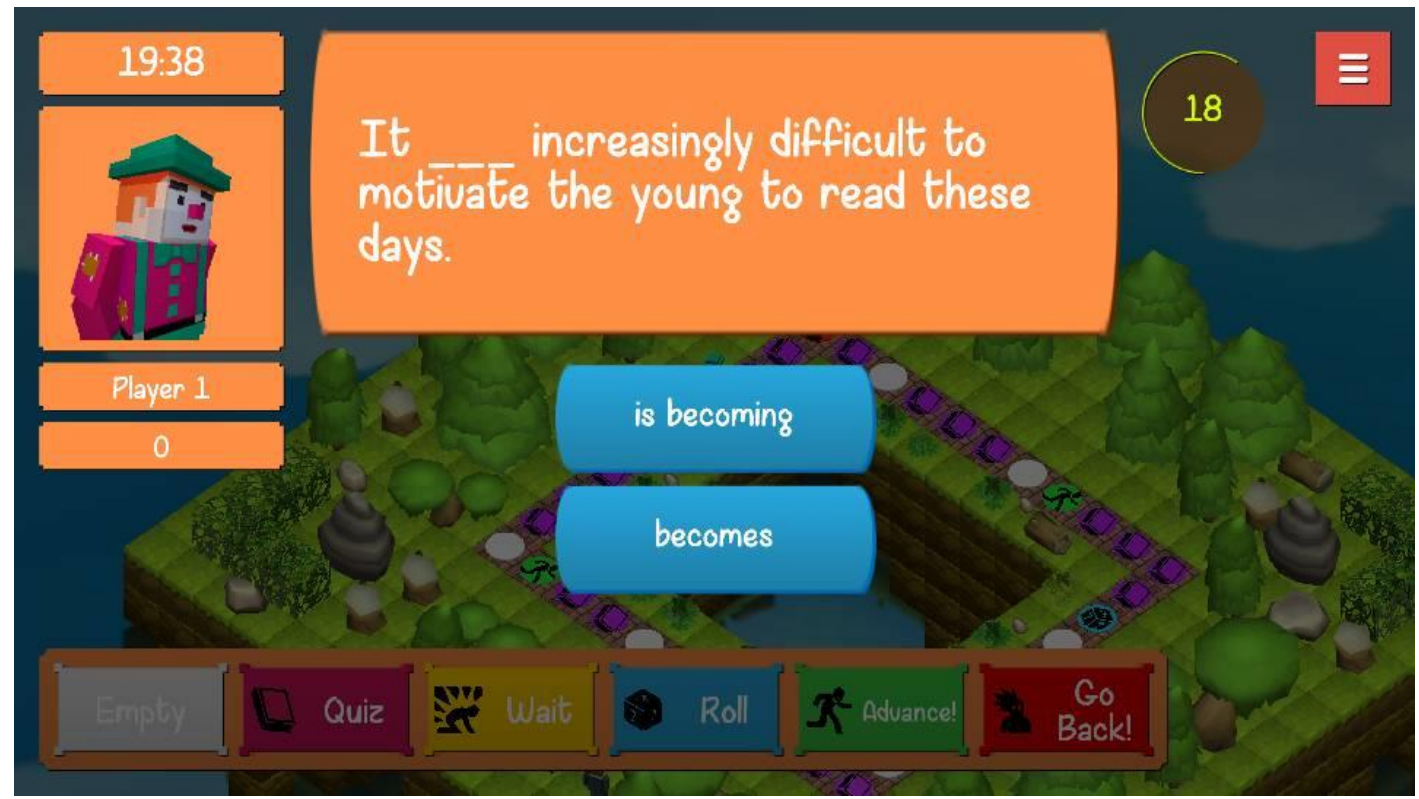

Figure 1: Two-answer options

Learners have to choose one correct answer from the two options shown in Figure 1. Once the learners click on the answer, they can immediately check their answer by clicking on the question mark (?) button (on the right-hand side) that provides feedback for each question (Figure 2). 


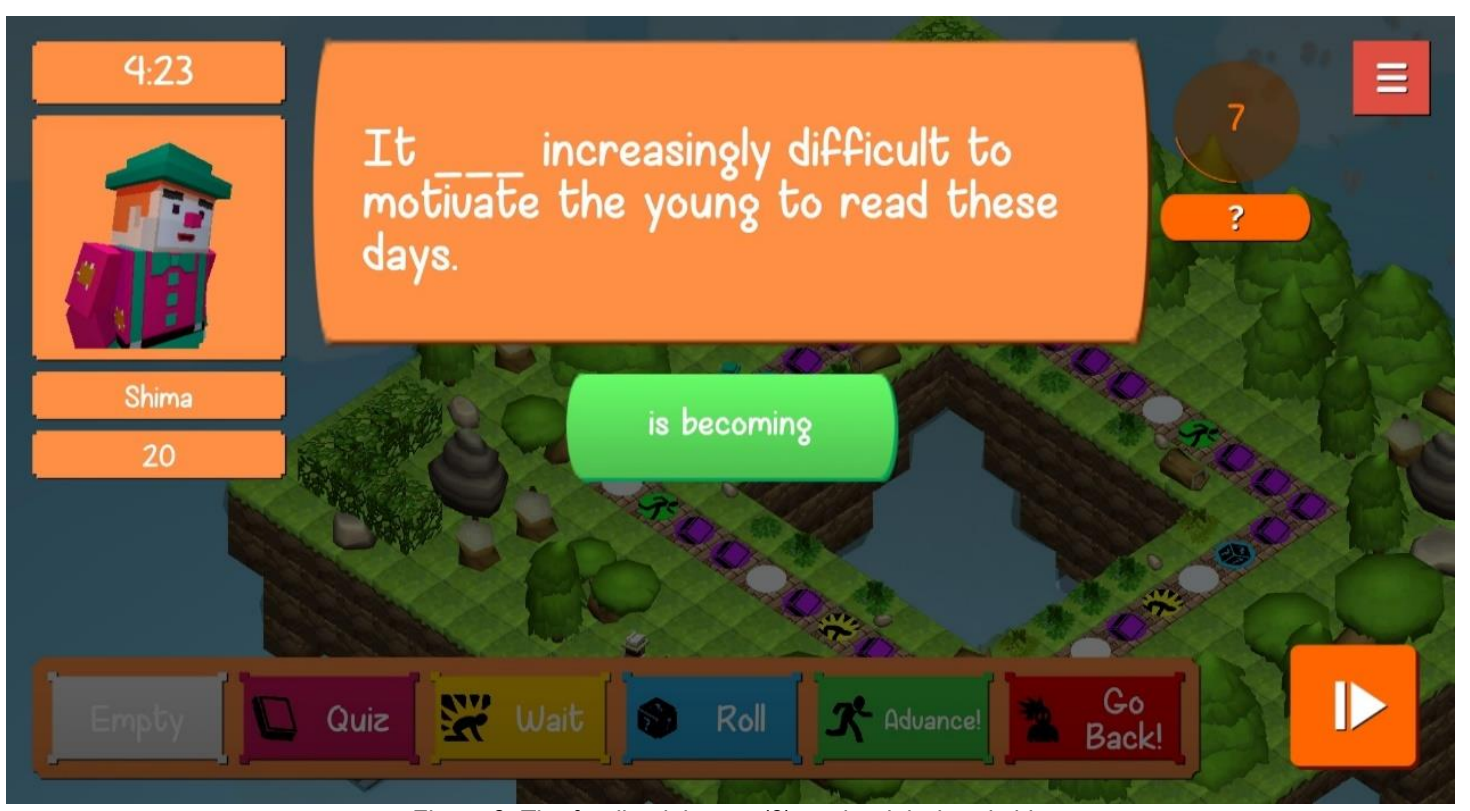

Figure 2: The feedback button (?) on the right-hand side

An example of the feedback is below in Figure 3:

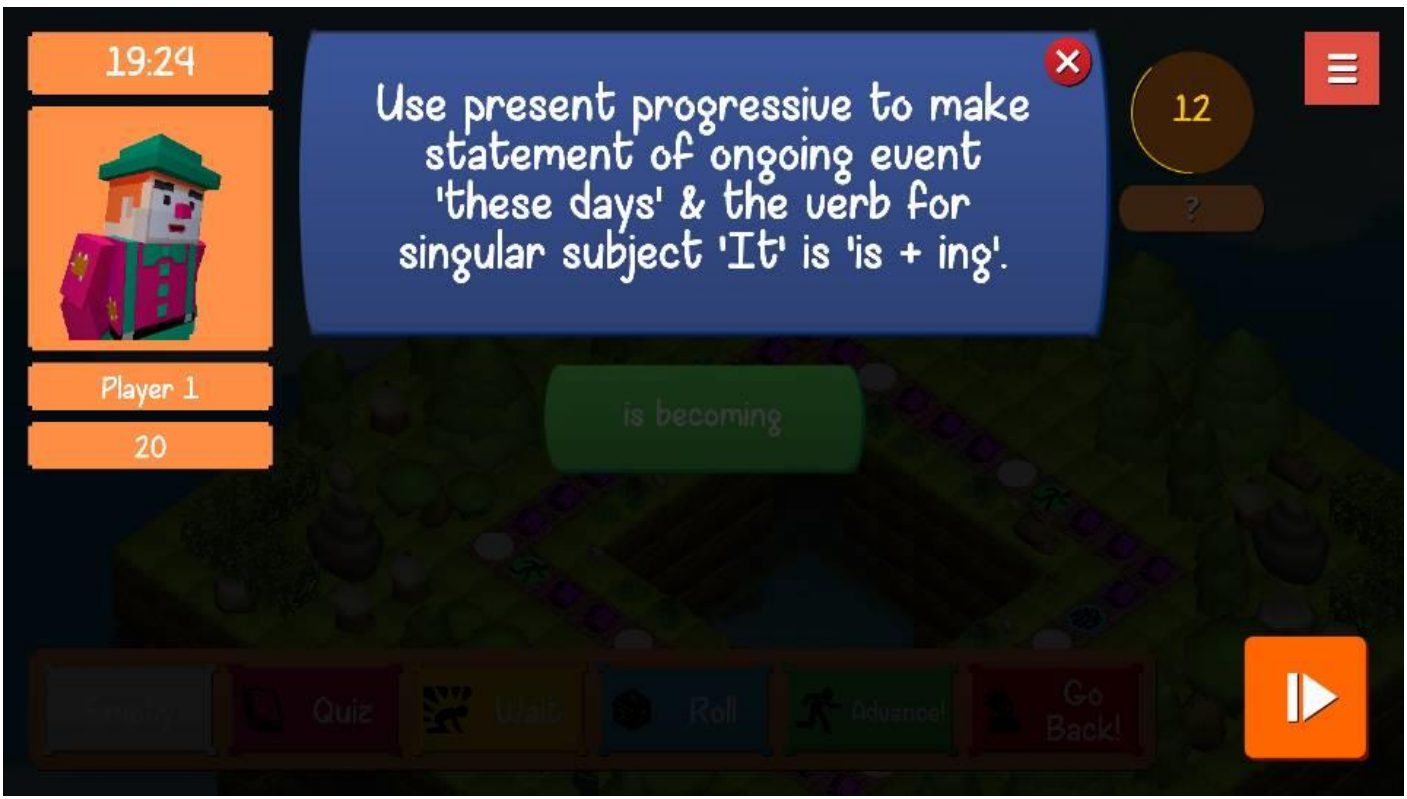

Figure 3: Feedback on the answer 


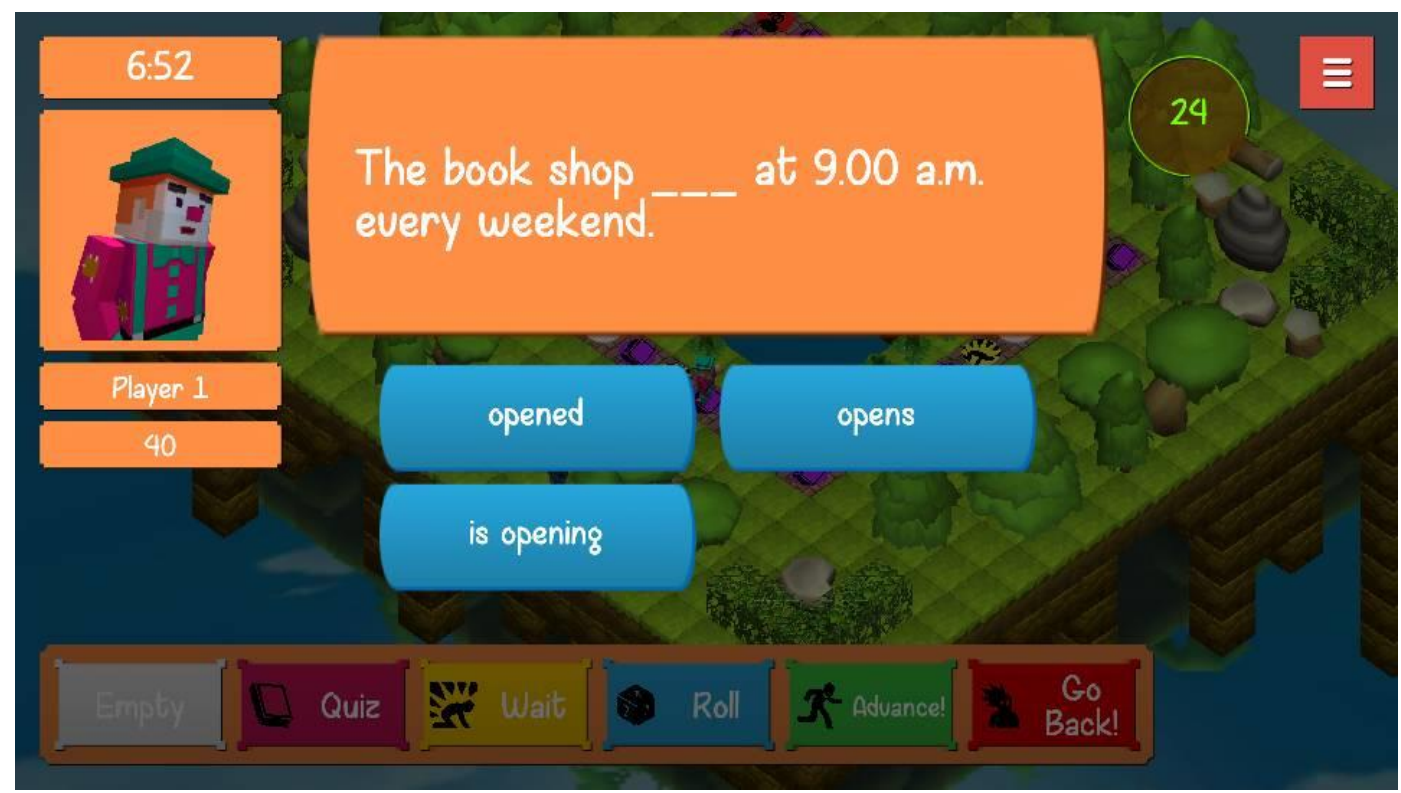

Figure 4: Three-answer options

Learners may choose one correct answer from the three options given.

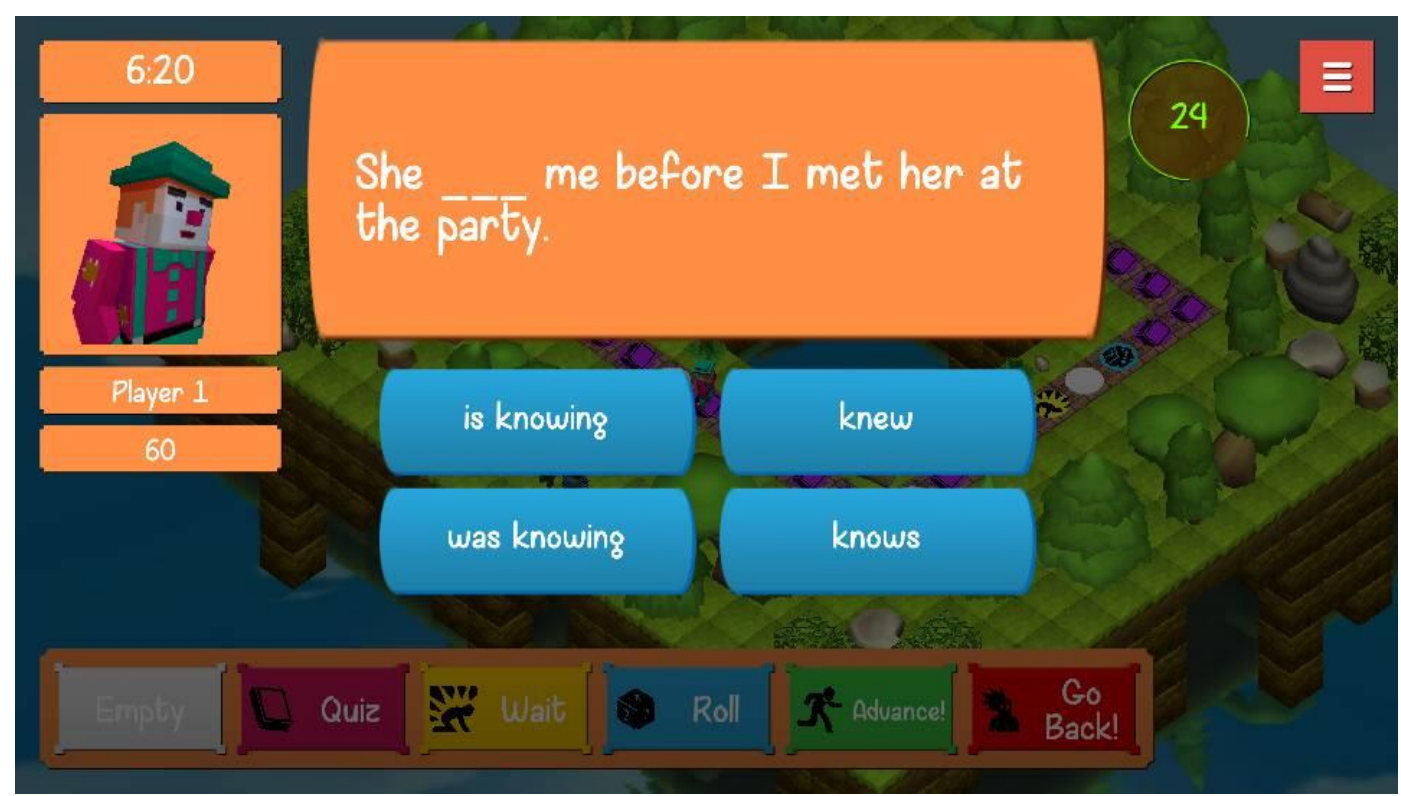

Figure 5: Four-answer options

One correct answer is from the four options available.

The following section highlights the rationale for the elements from the Theory of Variation used that support the design of questions with two-, three- and four-answer options. It presents (i) the patterns of variation involved, (ii) the patterns of the questions, (iii) invariants, (iv) variants, (v) what is to be discerned by learners? And (vi) what are the elements used that support the design of the questions? As described below:

i. $\quad$ The patterns of variation involved (Marton et al., 2004, p.16-17).

Contrast - to see the difference (variation) between different values

Fusion - to use several critical aspects simultaneously

ii. The patterns of the questions: The sentences are similar, but in two, three and four different tenses and aspect. The students have to choose the correct tense or aspect by checking the timeline, the subject-verb agreement, singular versus plural or the context of the sentences.

iii. Invariants: The object, actions and events

iv. Variants: Tense, aspects of the action, verb and meaning

v. What is to be discerned by learners? 
a) To recognize and understand how time markers, time referencing and the context indicate the series of events. Also, to determine the concept of the relationship of the action to the present time.

b) To recognize the correct tense and aspect to show the sequence of events in the context.

vi. What are the elements used that support the design of the questions?

Firstly, the questions are arranged using answers with two options to allow learners to fuse the critical aspect of two tenses or aspect at a time, for instance, varying:

a) simple present and present progressive,

b) simple present and simple past,

c) simple past and past progressive

Here learners have to use the contrast element to compare and contrast the pair to see the differences between simple present and present continuous for example, and be able to determine the appropriate use of each tense by referring to time reference, context, a series of events and the connection of the action with the present. The contrast will alert learners on the differences in the critical features of tenses and aspect (Lo, 2012). Some of the essential elements related to tenses and aspect include:

1. What makes learning to use simple present, present progressive, simple past and past progressive difficult for learners?

2. What makes simple present, present continuous, simple past and past progressive different from each other in terms of grammar rules?

3. When to use simple present, present continuous, simple past and past progressive?

4. How to use simple present, present progressive, simple past and past progressive?

Therefore, the researchers designed the questions by considering the possible critical features that can serve as clues for learners in choosing the correct answers. The Theory of Variation propagates that to experience what simple present is, learners must experience other tense or aspect (such as present progressive) as well. Only after having the knowledge of the additional value can the learners discern the specific tense of a simple present (Lo, 2012).

Secondly, learners have to fuse the tenses and aspect two at a time: simple present and present progressive or simple past and past progressive, three at a time: simple present, present continuous and simple past together and finally, all four option answers together: simple present, present continuous, simple past and past progressive. By showing two, there and four tenses and aspect together, their meanings could be more apparent to learners and would increase their possibility to learn them (Lindström, 2017). Fusion is applied when all the tenses and aspect are used simultaneously. At this stage, students have to consider when and how to use each grammar tense and aspect correctly and compare and contrast more than one critical feature simultaneously. By using contrast and fusion, learners are made aware that language consists of different grammar usage that construes meaning. Learners can also discern how grammar works through the examples of grammar usage and not from knowing rules alone. In addition to semantic levels, the questions appear in three types of difficulties; for instance, it began with two-answer options, three-answer options and followed by four answer options. The rationale for such an arrangement is to enable learners to grasp the tenses and aspect gradually.

\subsection{Discussion}

In introducing the tenses and aspect two at a time, followed by three at a time and finally four at a time, elements of contrast and fusion from the theory were applied. Variation does not only enable learners to differentiate and to distinguish the use of each tense and aspect but also to highlight that without seeing the difference, it is challenging to discern similarities. According to the Theory of Variation, depending entirely on similarities alone is incomplete. Lo (2012) and Marton and Pang (2013) believe that to be able to understand an element requires an understanding of the differences (variation) among items. Discernment would not be possible without seeing differences and without having to experience two different aspects concurrently. Analogically, the idea of 'sweet' cannot exist without the concept of 'sour'. If everything in the world is of the same taste, then we would not be able to discern sweetness, similarly by experiencing the difference between 'sweet' and 'sour' that the concept of 'sourness' will be observed. Of course, some learners can contrast what they have previously known with what the teacher has taught in class by doing well in the exam. The ability determines why some learners are successful than others. However, teachers can always extend the same opportunity to other learners by letting them see the difference between the two objects and at the same time by using the contrast element. Thus, when teaching learners what simple present is, the teacher should also show them what simple present is not, by comparing it with present progressive, simple past or past progressive. Thereby, learners will understand the critical features of the simple present with other non-examples (present continuous, simple past and past continuous). Contrasting simple present with other non-examples enables the essential elements of the simple present clearer to learners (how to use it, when to use it, what is the singular and plural and what are the time phrases, i.e. usually, always, often).

The element of fusion involved when all the tenses and aspect were introduced concurrently. First, by adding them two at a time, followed by three at a time and finally four at a time. The theory posits that a powerful way of understanding an object is to expose multiple features altogether (Lindström, 2017). Here the idea is to vary the critical functions (the verbs) for the learners to discern while keeping the subject, object and event constant. To understand an object sometimes depend on the concurrent focus of a few critical features and how they connect to one another. The simultaneous focus will then bring a better understanding of tenses and aspect. 


\subsection{Conclusion \& Recommendations}

Successful learning activity helps learners to learn better. The use of the elements in the Theory of Variation guided the researcher to design the learning materials in TBT and allows learners to experience the variation of critical features (what is the difficult aspect in learning grammar) for effective learning. The Theory of Variation provides an alternative means for teachers to teach a challenging subject like grammar. The important term highlighted in the Theory of Variation is ways of seeing. To assist learners in understanding a subject matter, we must first help learners to develop powerful ways of seeing to improve learning. The Powerful ways of seeing can be developed by helping learners to focus on certain important features of grammar tenses and aspect to enhance learning. It is also important for teachers to cater to learners' learning diversity, learning flexibility, and innovative teaching techniques to create a successful learning environment. It is also important for more empirical studies to determine educators' views on the effects of the game to improve teaching and learning further.

\section{Acknowledgements}

Our thanks and appreciation go to Prof. Lo Mun Ling from The Hong Kong Institute of Education, Hong Kong, for the valuable comments in the development of the questions in the game.

\section{References}

Annie, T. S. Y. (2011). Learning english tenses through the theory of variation. Journal of Asia TEFL, 8(2), 145-167.

Bazzaza, M. W., Alzubaidi, M., Zemerly, M. J., Weruga, L., \& Ng, J. (2016). Impact of Smart Immersive Mobile Learning in Language Literacy Education. IEEE, (April), 443-447.

Bikowski, D. (2018). Technology for Teaching Grammar. TESOL Encyclopedia of English Language Teaching.

Bowden, J., \& Marton, F. (1998). The University of learning. London, Kogan Page.

Chomsky, \& Halle. (1991). The Sound Pattern of English (MIT Press).

Embi, M. A., \& Amin, M. Z. M. (2010). Strategies for successful English Language Learning (SELL). Karisma Publications Sdn. Bhd. Shah Alam.

Ganapathy, M., Shuib, M., \& Azizan, S. N. (2016). Malaysian ESL students' perceptions on the usability of a mobile application for grammar test: A case study of ESL undergraduates in universiti sains Malaysia. 3L: Language, Linguistics, Literature, 22(1), 127-140.

Harmer, J. (1991). The Practice of English language Teaching (Longman, p. 22).

Klopfer, E., Sheldon, J., \& Chen, V.-H. (2011). Ubiquitous games for learning (UbiqGames)Weatherlings, a worked example. Computer Assisted Language Learning https://doi.org/http://dxdoi.org/10.111/j.1365-2729.2011.00456.x

Krasniuk, I., \& Kryvych, M. (2016). Learning foreign languages in context: Pros and cons of using modern computer technologies. IEEE, 6, 838-841. https://doi.org/10.1109/TCSET.2016.7452200

Larsen-Freeman. (1991). Research on language teaching methodologies: A review of the past and an agenda for the future. Foreign Language Research in CrossCultural Perspective, 119-132.

Larsen-Freeman. (2015). Research into practice: Grammar learning and teaching. Language Teaching, 48(02), 263-280. https://doi.org/10.1017/S0261444814000408

Lindström, C. (2017). Two tenses are better than one. Emerald, 6(2), 124-134. https://doi.org/10.1108//JLLS-10-2016-0034

Lo, M. L. (2012). Variation Theory and the Improvement of Teaching and Learning. Gothenburg Studies in Educational Sciences 323. Goteborgs Universitet. https://doi.org/10.1007/s35834-013-0078-0

Mahalingam, K., \& Embi, M. A. (2017). Learning-to-learn grammar module: an evaluation among primary esl learners. Journal of Education and Social Sciences, 6(2), $88-96$.

Matsumoto, Y., \& Dobs, A. M. (2017). Pedagogical Gestures as Interactional Resources for Teaching and Learning Tense and Aspect in the ESL Grammar Classroom Language Learning, (March), 7-42. https://doi.org/10.1111/lang.12181

Marton, \& Booth. (1997). Learning and awareness. Mahwah, New Jersey, Lawrence Erlbaum Associates

Marton. (2015). Necessary conditions of learning. Routledge, New York, NY.

Marton, F., \& Pang, M. F. (2006). On Some Necessary Conditions of Learning. Journal of the Learning Sciences, 15(2), 193-220. https://doi.org/10.1207/s15327809jls1502_2

Marton, Runesson, U., \& Tsui, A. B. M. (2004). The space of learning. Mahwah, NJ: Lawrence Erlbaum.

Marton, \& Morris. (2002). What matters? Discovering critical conditions of classroom learning. Goteborg: Acta Universitatis Gothoburgensis. 
Marton, \& Tsui, A. B. M. (2004). Classroom discourse and the space of learning. Mahwah, New Jersey, Lawrence Erlbaum Associates.

Marton, \& Runesson, U. (2003). The space of learning. In Symposium Improving Learning, Fostering the will to learn, European Association for Research on Learning and Instruction, Padova, Italy.

Ott, G. (2017). Exploring Variation Theory in form-focused language teaching. Teaching the present perfect in upper secondary EFL. CELT Matters, 1, 9-29.

Krasniuk, I., \& Kryvych, M. (2016). Learning foreign languages in context: Pros and cons of using modern computer technologies. IEEE, 6, 838-841. https://doi.org/10.1109/TCSET.2016.7452200.

Roy, J. (2014). The perfect approach to adverbs, applying variation theory to competing models. ProQuest Dissertations and Theses. https://doi.org/10.1007/s13398-0140173-7.2

Rozina, Shima, T. N., Mohamed Ismai, Rahmah, L. Y. \&, \& Hafiza, A. (2017). Mobile Assisted Language Learning (MALL) In Developing Second Language Learners' understanding of grammar. Journal of Academia UiTM Negeri Sembilan, 5, 187-208.

Sanchez, J., \& Olivares, R. (2011). Problem solving and collaboration using mobile serious games. Computers \& Education, $1943-1952$.

Shuib, Abdullah, A., Ismail, I., \& Siti Nur Afiqah, Z. (2013). The feasibility of teaching English Grammar via sms. Spectrum: Studies in Language, Literature, Translation and Interpretation, 9, 133-144.

Shuib, M., Amelia, A., Azizan, Siti Norbaya, \&, \& Gunasegaran, T. (2015). Designing an Intelligent Mobile Learning Tool for Grammar Learning ( i-MoL ). IJIM, 9(1), 4146.

Thorsten, A. (2015). How teachers' practice knowledge is used and challenged in a learning study using variation theory as a tool. Emerald, 4(3), $274-287$.

Tong, S. Y. A. (2012). Applying the theory of variation in teaching reading. Australian Journal of Teacher Education, 37(10).

Ur, P. (1996). A Course in Language Teaching, Practice and Theory (Cambridge, p. 77). 